\title{
Ligation of Patent Ductus Arteriosus via Anterior Thoracotomy in Preterm Infants: 10-Year Experience
}

\author{
Arif Selcuk ${ }^{1}$, Murat Çiçek ${ }^{2}$, Okan Yurdakök ${ }^{1}$, Yiğit Kılıç ${ }^{1}$, Filiz İzgi Coşkun ${ }^{1}$, Hasan \\ Erdem $^{3}$, Turkay Sarıtas ${ }^{4}$, Emine Hekim Yilmaz ${ }^{1}$, Oktay Korun ${ }^{1}$, Firat Altin ${ }^{1}$, Ahmet \\ Sasmazel $^{1}$, and Numan Aydemir ${ }^{1}$ \\ ${ }^{1}$ Dr Siyami Ersek Thoracic and Cardiovascular Surgery Training and Research Hospital \\ ${ }^{2}$ Doktor Siyami Ersek Gogus Kalp ve Damar Cerrahisi Egitim ve Arastirma Hastanesi \\ ${ }^{3}$ Kartal Kosuyolu Training and Research Hospital \\ ${ }^{4}$ Istanbul Medipol University
}

September 7, 2020

\begin{abstract}
BACKGROUND The aim of this study is to describe the short-term and mid-term outcomes of the preterm infants who underwent patent ductus arteriosus (PDA) ligation in by anterior mini-thoracotomy. METHODS Data of 103 preterm infants who underwent PDA ligation by anterior mini-thoracotomy between 2009 and 2019 were retrospectively reviewed. PDA was clipped through an anterior mini-thoracotomy at the 2nd intercostal space. Outcomes were defined according to complications, morbidity and mortality rates within the postoperative 30 days and one year. RESULTS The median weight of the patients during the operation was 900 (IQR800-1125 g) grams and the lowest body weight was 460 grams. The median age at the operation was 21 (IQR14,5-29 days) days. In three patients (3\%) there was intraoperative bleeding from the PDA that required transition to median sternotomy. In one patient (1\%) residual PDA was seen and this patient was reoperated on the 4th postoperative day. One patient (1\%) underwent surgical revision for chylothorax and chylomediastinum causing late cardiac tamponade on the 26 th postoperative day. Twelve patients (12\%) died in the first 30 days postoperatively. Six patients (6\%) died between the thirtieth day and a year. CONCLUSIONS After a decade and over a hundred patients with PDA ligation through anterior mini-thoracotomy in preterm infants is still the main procedure of choice in this patient group in our clinic. Our outcomes demonstrate the safety of this approach and we believe that it can be reproducible.
\end{abstract}

\section{Hosted file}

text.doc available at https://authorea.com/users/356812/articles/479607-ligation-of-patentductus-arteriosus-via-anterior-thoracotomy-in-preterm-infants-10-year-experience 

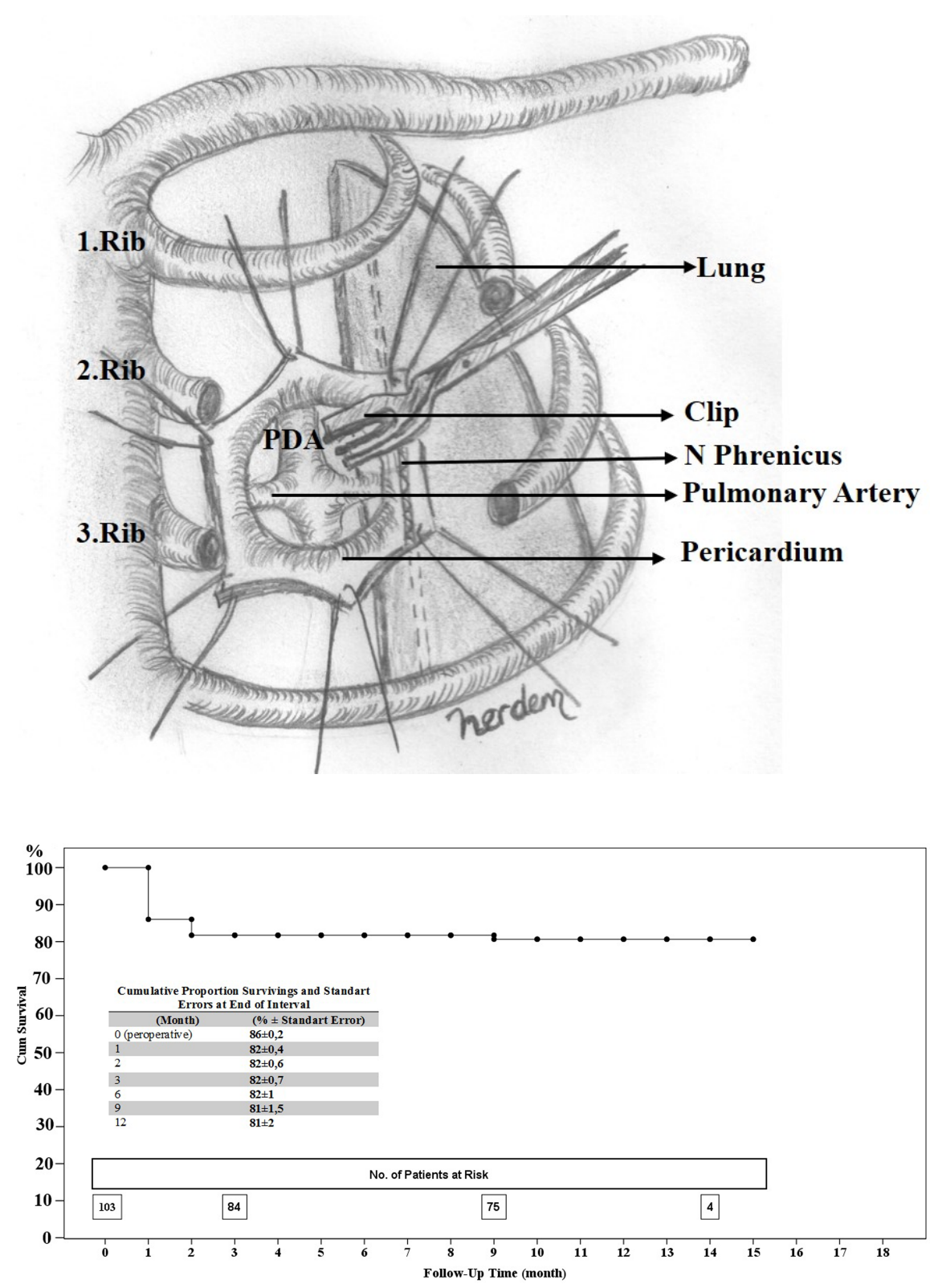